\title{
"Below average" self-assessed school performance and Alzheimer's disease in the Aging, Demographics, and Memory Study
}

\author{
Kala M. Mehta ${ }^{\mathrm{a}, \mathrm{b}, \mathrm{c}, *}$, Anita L. Stewart ${ }^{\mathrm{c}, \mathrm{d}}$, Kenneth M. Langa ${ }^{\mathrm{e}, \mathrm{f}}$, Kristine Yaffe $^{\mathrm{b}, \mathrm{g}}$, \\ Sandra Moody-Ayers ${ }^{\mathrm{a}, \mathrm{g}}$, Brie A. Williams ${ }^{\mathrm{a}, \mathrm{g}}$, Kenneth E. Covinsky ${ }^{\mathrm{a}, \mathrm{g}}$ \\ ${ }^{a}$ Division of Geriatric Medicine, University of California at San Francisco, San Francisco, CA, USA \\ ${ }^{b}$ San Francisco Veterans Affairs Medical Center, San Francisco, CA, USA \\ ${ }^{c}$ Medical Effectiveness Research Center for Diverse Populations, University of California at San Francisco, San Francisco, CA, USA \\ ${ }^{d}$ Institute for Health and Aging, University of California at San Francisco, San Francisco, CA, USA \\ ${ }^{e}$ Division of General Medicine, Department of Medicine and the Institute for Social Research, University of Michigan, Ann Arbor, MI, USA \\ ${ }^{f}$ Veterans Affairs Center for Practice Management and Outcomes Research, Ann Arbor, MI, USA \\ ${ }^{g}$ Department of Psychiatry, Department of Neurology, and Department of Epidemiology, University of California, \\ San Francisco, San Francisco, CA, USA
}

Abstract

Background: A low level of formal education is becoming accepted as a risk factor for Alzheimer's disease (AD). Although increasing attention has been paid to differences in educational quality, no previous studies addressed participants' own characterizations of their overall performance in school. We examined whether self-assessed school performance is associated with AD beyond the effects of educational level alone.

Methods: Participants were drawn from the population-representative Aging, Demographics, and Memory Study (ADAMS, 2000-2002). The ADAMS participants were asked about their performance in school. Possible response options included "above average," "average," or "below average." The ADAMS participants also underwent a full neuropsychological battery, and received a research diagnosis of possible or probable AD.

Results: The 725 participants (mean age, 81.8 years; $59 \%$ female; $16 \%$ African-American) varied in self-assessed educational performance: $29 \%$ reported "above average," $64 \%$ reported "average," and $7 \%$ reported "below average" school performance. Participants with a lower self-assessed school performance had higher proportions of AD: $11 \%$ of participants with "above average" self-assessed performance had $\mathrm{AD}$, as opposed to $12 \%$ of participants with "average" performance and $26 \%$ of participants with "below average" performance $(P<0.001)$. After controlling for subjects' years in school, a literacy test score (Wide-Range Achievement Test), age, sex, race/ethnicity, apolipoprotein E- $\varepsilon 4$ status, socioeconomic status, and self-reported comorbidities, respondents with "below average" self-assessed school performance were four times more likely to have AD compared with those of "average" performance (odds ratio, 4.0; 95\% confidence interval, 1.2-14). "Above average" and "average" self-assessed school performance did not increase or decrease the odds of having AD (odds ratio, $0.9 ; 95 \%$ confidence interval, $0.5-1.7)$.

Conclusions: We suggest an association between "below average" self-assessed school performance and $\mathrm{AD}$ beyond the known association with formal education. Efforts to increase cognitive reserve through better school performance, in addition to increasing the number of years of formal education in early life, may be important in reducing vulnerability throughout the life course.

(C) 2009 The Alzheimer's Association. All rights reserved.

*Corresponding author. Tel.: 415-221-4810, extension 3984.

E-mail address: Kala.Mehta@ucsf.edu 


\section{Introduction}

Lower formal education is a consistent risk factor for Alzheimer's disease (AD), as summarized by a recent meta-analysis [1]. As early as the 1990s, Zhang et al. reported that poorly educated Chinese subjects were more likely to have dementia than those with higher levels of education [2]. The brain-reserve and cognitive-reserve hypotheses followed, as conceptual models of the mechanism of action [3-5]. Brain reserve refers to an individual's brain structures, including neurons in key areas of the brain related to learning and memory. A common metaphor used for brain reserve is that it is akin to computer hardware. Similarly, following this metaphor, cognitive reserve is akin to computer software, wherein the reserve is developed over early life. Education and other early-life experiences may influence the reserve built up in each individual. Those with a greater reserve may be able to function longer without reaching a threshold of cognitive impairment, compared to people with a lower reserve. This might explain why clinical symptoms may appear earlier for people with a low level of formal education and other different contextual experiences (e.g., low early linguistic ability and early intelligence quotient), compared to people with higher formal education. Despite a vast array of research, evaluating education using years of formal education may not be sufficient.

Less is known about educational quality differences and the risk for AD. For example, in one study, cognitive-function test performances for nondemented African Americans were significantly lower compared with whites of a matched educational level [6]. Further work suggested that quality of education may be a better measure of cognitive reserve than level of education alone [7]. Literacy, another potential measure of educational quality/reserve, is linearly associated with cognitive function [8], and potentially mediates racial or ethnic differences in cognition [9].

Educational quality was previously defined broadly in terms of the desirable characteristics of learners (healthy, motivated students), processes (competent teachers using active pedagogies), content (relevant curricula), and systems (good governance and equitable resource allocation) [10]. A potential indicator of a healthy, motivated learner is perhaps the individual's self-rating of performance while in school. Despite this, no studies, to our knowledge, have examined the relationship between an individual's assessment of how well he or she performed in school (self-assessed school performance) and cognitive impairment or AD. Previous studies of performance did not address whether self-assessed school performance is essentially different from level of formal education received, level of literacy, or low socioeconomic status (SES) in conferring a risk of AD. Our study addresses this gap by examining data from the Aging, Demographics, and Memory Study, a detailed study of dementia. We examined whether self-assessed school performance is an independent risk factor for $\mathrm{AD}$.

\section{Methods}

\subsection{Setting}

The Health and Retirement Study (HRS) is a cohort study of United States adults aged 50 years and above that has collected data from 1992 to the present. Because the primary purpose of this study is to examine the dynamics of older adults' incomes and wealth, it includes detailed measures of SES and self-reported health conditions. The HRS sample is derived from a multistage, clustered-area probability frame of over 60,000 housing units (for adults aged 50 to 64 years) and Medicare enrollment lists (for adults aged 65 years and above). There were 11,454 respondents in the 2000 wave of the HRS, and 10,321 respondents in the 2002 wave of the HRS, at age 70 years and above.

A complementary study, the Aging, Demographics, and Memory Study (ADAMS), was added to the parent HRS to examine dementia [11]. It identified 7000 respondents aged 70 years and above from the 2000 and 2002 HRS waves eligible for ADAMS [12,13]. A stratified sample of 1770 individuals was selected for eligibility in ADAMS, based on low to high cognitive-function performance [14]. Of 1770 selected individuals, 856 completed initial assessment [11,15,16], 227 died before the initial assessment could be completed, and 687 (39\%) refused or did not participate.

\subsection{Participants}

A nurse and a neuropsychology technician conducted an in-person, 3.5-hour evaluation with each of the 856 participants and with an informant familiar with each participant's medical history. A multidisciplinary conference (with a geropsychiatrist, neurologist, neuropsychologist, and cognitive neuroscientist) reviewed information and assigned a research diagnosis. For dementia diagnoses, the criteria were based on the Diagnostic and Statistical Manual for Mental Disorders version 3 revised, Diagnostic and Statistical Manual for Mental Disorders version 4, and National Institute of Neurological and Communicative Disorders and Stroke and the Alzheimer's Disease and Related Disorders Association. Of the 856 ADAMS participants, 131 received nondementia neurological diagnoses (e.g., Parkinson's or Huntington's disease) and were excluded from our study. Here, we primarily focus on the remaining 725 individuals, divided into four groups: 229 with AD, 71 cases of non-AD dementia (primarily vascular dementia), 118 with cognitive impairment (mild cognitive impairment, prodromal $\mathrm{AD}$, not meeting criteria for $\mathrm{AD}$, and cognitive impairment with cause unknown), and 307 who were considered to have normal cognitive functioning. Our primary objective was to contrast the $\mathrm{AD}$ group $(\mathrm{n}=$ $229)$ with those of normal cognitive functioning $(n=307)$. Other contrasts were pursued as sensitivity analyses. The present study was approved by the Institutional Review Board of the University of California at San Francisco and the San Francisco Veterans Administration Medical Center. 


\subsection{Measures derived from ADAMS}

Information on education and educational performance was derived from ADAMS from 2001 to 2003, including highest level of formal education received. In addition, our central measure was the question, "How well did you perform in school?" The response choices included "average," "above average," and "below average." We focused on this question because it is a general measure, and we felt that asking for more detailed recollections of past performance, e.g., asking for their exact grade point average, would make too many demands on memory, whereas asking too little would not provide the variance necessary to ensure a good predictor variable. We also queried whether the respondent had ever failed a subject, and whether the respondent was ever held back, given special instruction, or tutored. Literacy was assessed using the Wide-Range Achievement Test (WRAT-3), a measure of reading and literacy in the elderly, which has good test-retest reliability [17]. Respondents with the genetic risk factor apolipoprotein $E \& 4$ ( $A P O E \varepsilon 4$; either one or two alleles) were compared to those without the allele.

\subsection{Other Measures}

Several measures were obtained from the HRS. Race was based on self-report, and was categorized into the groups "white," “African American," or "other." Ethnicity was categorized as Hispanic or non-Hispanic. For the purposes of this study, race and ethnicity were divided into three mutually exclusive groups: white, not Hispanic (white); African American, not Hispanic (African American); and Hispanic of any race (Latino). Current SES was measured by total household income, and by total net worth or current value of all assets, including individual retirement accounts, stocks, or mutual funds, checking and savings, and real estate, minus all debt in 2000. Separate indicator variables were calculated for each chronic condition if the participant had a self-reported medical history of high blood pressure, diabetes mellitus, heart disease, or stroke in 2000. Early childhood SES was evaluated using four indicators [18]: parent with highest level of education ( $<8$ years, 8 to 11 years, or 12 or more years), self-reported perception of childhood family financial status as "poor" (family poverty), having to move during childhood because of financial difficulties (family hardship), or self-report that respondents had never lived with their father or the father was not alive during their childhood (father absent). Depressive symptoms were assessed in 2000, using a modified version of the Centers for Epidemiologic Study Depression Scale (CES-D) [19].

\subsection{Statistical analyses}

Characteristics were compared for participants with "below average," "average," and "above average" self-assessed school performance, using $\chi^{2}$ tests and $t$-tests where appropriate. The association between self-assessed school performance and AD was calculated using age-adjusted logistic regression models. We evaluated the outcome in three ways: 1$)$ contrasting $\mathrm{AD}$ patients $(\mathrm{n}=229)$ with the reference group of participants with normal cognitive status $(n=307)$; 2) contrasting all-cause dementia (AD participants and non-AD dementia participants combined, $\mathrm{n}=300$ ) with participants with normal cognitive function $(\mathrm{n}=307)$; and 3 ) calculating an ordinal logistic regression model with three groups: $\mathrm{AD}(\mathrm{n}=229)$, cognitive impairment $(\mathrm{n}=118)$, and normal cognitive status $(n=307)$.

We used a sequential adjustment of potential confounders, according to adjustment blocks approximating the timing of risk factors over a life course. First, demographics and genetics (gender, race, and presence of $A P O E \varepsilon 4$ ) were added to the age-adjusted model. To assess whether level of formal education mediated the relationship between educational performance and $\mathrm{AD}$, this factor was added to the model adjusting for age, demographics, and genetics. Then socioeconomic markers (either childhood or current) were added to the previous model. These included parents' educational level in years completed, family poverty experienced in childhood (yes/no), family hardship experienced in childhood (yes/no), whether the father was absent, respondent's current income, and total current value of assets, including individual retirement accounts, stocks, mutual funds, checking and savings, and real estate. An additional adjustment involved self-reported comorbidities: high blood pressure, diabetes, heart disease, and stroke. The final adjustments were for literacy score, as measured by WRAT-3, and separately, an adjustment for depressive symptoms, as measured by the CES-D.

We tested potential interactions between key risk factors and self-assessed school performance, including: 1) race/ethnicity, 2) gender, 3) median educational level, and 4) presence of the $A P O E \& 4$ allele. Each interaction was tested in a model additionally adjusted for age. All analyses were calculated in two ways, i.e., unweighted and using study weights. The weighted analyses used survey procedures in SAS 9.1 (SAS Institute, Cary, NC), to account for the complex survey design of ADAMS and HRS. We applied three weighting variables, using SAS survey procedures: the stratum variable (sestrat) was used to account for the sampling stratum, a cluster variable (seclust) was used to account for the clustering of data, and a sample weight (aasampwt) was used to account for differing sampling probabilities because of the oversampling of some groups. Because 36 participants used a proxy informant to answer the question regarding selfassessed school performance, we performed all analyses again, excluding those 36 participants.

\section{Results}

The 725 participants in ADAMS were on average 81.8 years old, and were more often female (59\%). Sixteen percent of the older adult participants were African American, 8\% were Latino, and the rest were white. Twenty-nine percent had one or two APOE $\varepsilon 4$ alleles. Subjects with "below 
Table 1

Characteristics of participants in the Aging, Demographics, and Memory Study $(\mathrm{n}=725)$

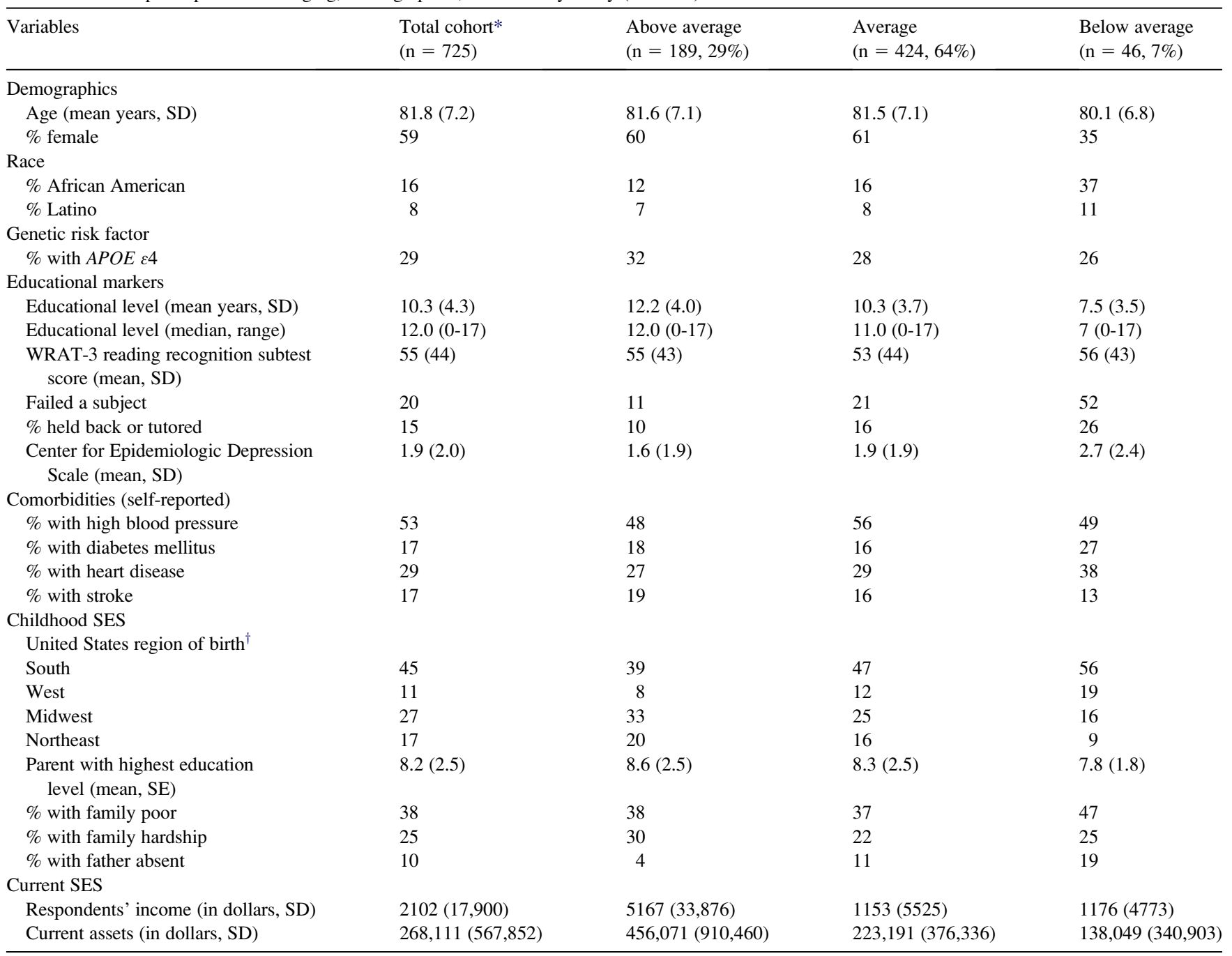

* Sixty-six participants with missing information on educational performance were excluded.

${ }^{\dagger}$ Sixty-one participants were missing information on region of birth.

average" self-assessed school performance were younger and comprised a higher proportion of men and nonwhite race/ethnicity groups. In terms of comorbidities and socioeconomic markers, those with "below average" self-assessed school performance had similar comorbidities and more of a socioeconomic burden compared with participants of average and above-average self-assessed school performance (Table 1).

The median level of education was 12 years. Overall, $7 \%$ of subjects reported "below average" school performance, $64 \%$ reported "average" school performance, and 29\% reported "above average" performance. Of participants who reported failing a subject in school, $11 \%$ reported "above average," $21 \%$ reported "average," and 52\% reported "below average" school performance $(P<0.001)$. Of participants who reported they had been held back, given special instruction, or tutored, $10 \%$ reported they had "above average" school performance, $16 \%$ reported "average" school performance, and 26\% reported "below average" school performance $(P<0.001)$.

Participants with lower self-assessed school performance had higher proportions of AD: $11 \%$ of participants with "above average" self-assessed performance, $12 \%$ of participants with "average" performance, and $26 \%$ of participants with "below average" performance had $\mathrm{AD}(P<0.001)$. A report of "below average" school performance was associated with $\mathrm{AD}$, adjusted for age (age-adjusted odds ratio (OR), 5.9; 95\% confidence interval (CI), 2.0-18). This relationship persisted after controlling for demographic characteristics and the presence of the genetic risk factor $A P O E \& 4(\mathrm{OR}$, $6.7 ; 95 \%$ CI, 2.2-21). This result was slightly attenuated after additional adjustment for years of formal education attained (OR, 4.8; 95\% CI, 1.5-16), and after additional adjustment for current and childhood socioeconomic indicators and comorbidity (OR, 4.2; 95\% CI, 1.2-15) (Table 2). We also adjusted for WRAT-3, a measure of literacy. After the addition 
Table 2

Educational performance and AD in ADAMS, with a series of adjustments (odds ratios and 95\% confidence intervals)

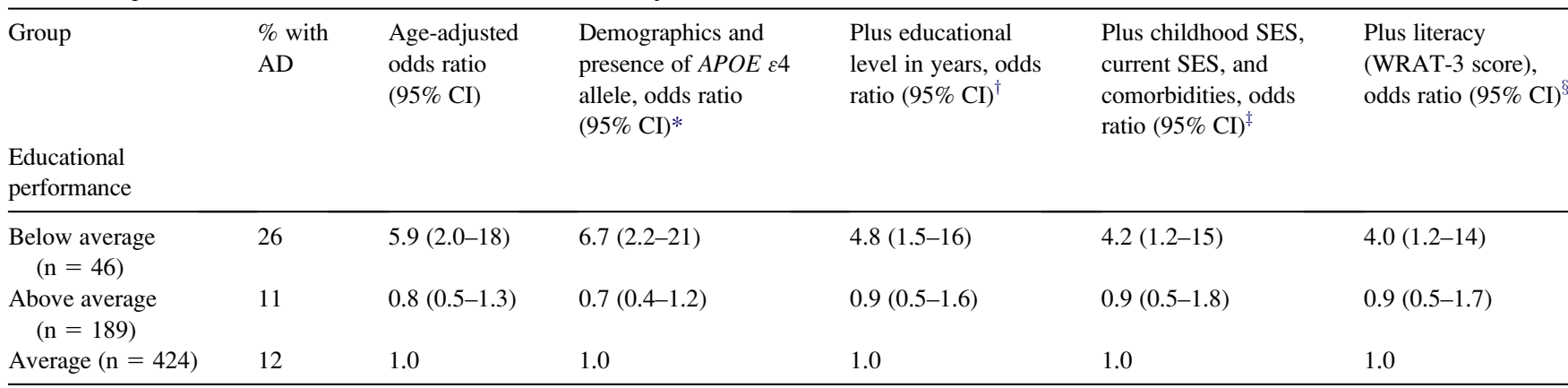

\footnotetext{
* Model was adjusted for age, age-squared, sex, race, and presence of APOE $\varepsilon 4$.

${ }^{\dagger}$ Model was also adjusted for respondent's level of education.

${ }^{\ddagger}$ Model was also adjusted for childhood SES (parents’ highest level of education in years, family poverty (yes/no), family hardship (yes/no), or whether the father was absent); current SES (respondents' income and total current assets); and comorbidities (self-reported medical history of high blood pressure, diabetes mellitus, heart disease, and stroke).

${ }^{\S}$ Model was also adjusted for WRAT-3 score.
}

of WRAT-3, the results were further slightly attenuated (OR, $4.0 ; 95 \%$ CI, 1.2-14). In the fully adjusted model, formal education attained was also associated with $\mathrm{AD}$, with each year in school associated with a $15 \%$ reduced odds of AD (OR, 0.84 ; 95\% CI, 0.76-0.92). However, when we added premorbid depression score as measured by a modified version of the CES-D in 2000, the results were significantly attenuated for "below average" self-assessed school performance (results not in a table) (OR, 3.7; 95\% CI, 0.8-17).

"Above average" educational performance was associated with a similar risk of AD compared with those with "average" performance, after adjustment.(OR, 0.7; 95\% CI, 0.4-1.2) Similar results were evident after additional adjustment for level of formal education attained and socioeconomic indicators. If participants reported failing a subject in school, being held back, being given special instruction, or being tutored in school, they were not at increased odds of AD, either alone or after adjustment (results not shown).

Because few participants had non-AD dementia and cognitive impairment, we undertook two analyses using combined outcomes. Participants reporting "below average" self-as- sessed school performance had a similar increased odds of all-cause dementia (AD and non-AD dementia combined; OR, 4.3; 95\% CI, 1.4-13). Participants reporting "below average" self-assessed school performance had increased odds of cognitive impairment, but not meeting the criteria for dementia. However, this analysis was of limited power (OR, 2.6; 95\% CI, 1.3-4.9) (Table 3). The model fit was adequate for all models; the c-statistic ranged from 0.85 to 0.89 .

To ascertain whether the results differed for particular subgroups, we calculated four possible interactions: sex (men/women), APOE $\varepsilon 4$ allele (present/absent), level of formal education (12 years or more/less than 12 years), and race/ ethnicity (non-Hispanic white compared with African American and Latino). No significant interaction was present for sex and self-assessed school performance $(P=0.51)$, presence of $A P O E \& 4$ and self-assessed school performance $(P=0.28)$, level of formal education and self-assessed school performance $(P=0.07)$, and race/ethnicity and selfassessed school performance $(P=0.10)$.

Because 36 respondents had proxy informants, all of the above analyses were calculated excluding these 36

Table 3

Educational performance and AD, all-cause dementia, and cognitive impairment in ADAMS (odds ratios and 95\% confidence intervals)

\begin{tabular}{|c|c|c|c|c|c|}
\hline Models & Predictors & Group & $\begin{array}{l}\text { Possible/probable AD } \\
\text { ( } 229 \text { with possible/ } \\
\text { probable AD/307 normal), } \\
\text { odds ratio }(95 \% \mathrm{CI})\end{array}$ & $\begin{array}{l}\text { All-cause dementia ( } 300 \text { with } \\
\text { dementia/307 normal), odds } \\
\text { ratio }(95 \% \mathrm{CI})\end{array}$ & $\begin{array}{l}\text { Cognitive impairment (ordinal outcome } \\
\text { with } 118 \text { cognitively impaired/229 with } \\
\text { AD/307 normal), odds ratio ( } 95 \% \mathrm{CI} \text { ) }\end{array}$ \\
\hline \multirow[t]{2}{*}{ Model 1} & \multirow[t]{2}{*}{$\begin{array}{l}\text { Educational } \\
\text { performance }\end{array}$} & $\begin{array}{l}\text { Below average } \\
\quad(\mathrm{n}=46)\end{array}$ & $4.0(1.2-14)$ & $4.3(1.4-13)$ & $2.6(1.3-4.9)$ \\
\hline & & $\begin{array}{l}\text { Above average } \\
\quad(\mathrm{n}=189)\end{array}$ & $0.9(0.5-1.7)$ & $0.9(0.5-1.6)$ & $1.0(0.7-1.6)$ \\
\hline
\end{tabular}

NOTE. Models were adjusted for age; age-squared; sex; race; presence of APOE $\varepsilon 4$; respondent's level of education; childhood SES, i.e., parents' highest level of education in years, family poverty (yes/no), family hardship (yes/no), or whether father was absent; current SES (respondents' income and total current assets); comorbidities (self-reported medical history of high blood pressure, diabetes mellitus, heart disease, and stroke); and literacy, as assessed by WRAT-3 score. 
participants. The conclusion of all analyses remained the same with the exclusion of these participants, and thus we report on all models including these 36 participants.

\section{Discussion}

Our results extend the well-established inverse relationship between formal education and AD. This study suggests that "below average" self-assessed school performance is associated with fourfold increased odds of $\mathrm{AD}$ after accounting for the known effects of formal education and literacy. In addition, these findings persisted after adjustment for several key factors, including the presence of $A P O E \varepsilon 4$, childhood and current socioeconomic indicators, and self-reported comorbidities. Our results also show that the relationship between a "below average" self-assessed school performance and $\mathrm{AD}$ is similar for vulnerable groups, including participants with low levels of formal education and of nonwhite race/ethnicity.

Several important studies linked educational attainment in young adulthood and the late-life risk of $\mathrm{AD}$, supporting the brain-reserve and cognitive-reserve hypotheses [2-5]. Brain reserve involves the concept that individuals begin life with brain structures, including neurons, in key areas of the brain related to learning and memory. A common metaphor used for brain reserve is that it is akin to computer hardware. Similarly, following this metaphor, cognitive reserve is the computer's software, wherein the reserve is developed over early life. Education and other early-life experiences may influence the reserve built up in each individual. Those with a higher reserve may be able to function longer without reaching a threshold of cognitive impairment, compared to people with a lower reserve. Educational level was used to approximate brain and cognitive reserves, because it modified the association between neuritic plaques and cognitive function in the Religious Orders Study [20]. Further work suggests that literacy, another potential measure of educational quality/reserve [21], is linearly associated with cognitive function [8] and potentially mediates race/ethnic differences in cognition [9]. Although our data do not directly speak to this issue, we believe that self-assessed school performance may have an impact on increasing cognitive reserve (i.e., it will provide strategies to help delay the onset of clinical symptoms of $\mathrm{AD}$, without affecting the neuropathological course of $\mathrm{AD}$ ).

Few studies examined the metrics of educational performance. In childhood, educational performance is linked to poor health [22]. To our knowledge, no studies in the medical literature have correlated self-reported school performance in old age with actual performance at younger ages. In older age, overall self-assessed school performance has not been studied per se, but related constructs were studied. For example, idea density at age 20 years was associated with decreased risk of $\mathrm{AD}$ in older adulthood. Because these subjects were part of a religious order (nuns), these findings may not be generalizable [23]. In another study, higher public school intelligence quotient scores from 1944 to 1946 were associated with $50 \%$ decreased odds of a combined outcome of mild cognitive impairment and dementia 60 years later [24]. A similar study in Scotland suggested that the mean mental ability scores at age 11 years were lower in patients who developed dementia compared with age-matched control subjects [25]. The latter two studies were limited because they were restricted to performance on one test in early life, and were limited to a defined geography. Our findings extend this previous work, suggesting that a more general metric, i.e., a report of "below average" educational performance, may be yet another risk factor for AD beyond the effects of educational performance, mental ability/intelligence quotient, or linguistic ability - but all are probably related to, or are markers for, cognitive reserve in early life.

A recent review summarized early-life risk factors and $\mathrm{AD}$, and found varying results [26]. The strongest associations between early-life socioeconomics and $\mathrm{AD}$ were evident in people with the APOE $\varepsilon 4$ allele [27,28]. We did not find a stronger effect of "below average" self-assessed school performance in $A P O E$ \&4 allele carriers. Moreover, adjusting for early-life or late-life socioeconomic indicators did not alter our results appreciably. This suggests that the effects of "below average" educational performance are independent of poor socioeconomic conditions, and may signify that educational performance captures vulnerability beyond resource dissolution alone.

Previous studies suggest that educational quality may vary by race/ethnicity. These studies indicated that race differences in performance on cognitive function tests exist after matching on educational level [21,29]. Our evaluation of an interaction between race/ethnicity and self-assessed school performance suggests that the effects of "below average" educational performance are similar for African Americans compared with whites. This may be because the African Americans of this generation have had different educational-quality opportunities compared with white adults of the same generation [30-35]. Considering the strength of this self-report of school performance with $\mathrm{AD}$, we suggest that further studies, particularly in diverse racial and ethnic groups, evaluate a simple self-report of educational performance as a good surrogate marker for cognitive reserve when other markers of childhood performance are unavailable. One possible explanation for the mechanism by which self-assessed school performance and later dementia are linked may involve self-stereotype or stereotype threat [36]. If individuals believe they are "not academic," they may consequently avoid cognitively demanding tasks (or at least activities generally perceived to be demanding) or possible skill development in the future. Other possible mechanisms may involve related risk factors, such as preschool cognitive skills or depressive symptoms, that influence both actual or assessed school performance and later AD risk [37]. We believe that depressive symptoms and assessment of school performance may be related concepts, and that depressive symptoms are not simple confounders or mediators in this instance. 
Some limitations of our study deserve comment. Perhaps the strongest source of potential bias is the reliance on self-report of educational performance and the limited number of respondents who reported "below average" educational performance. As a result, the confidence intervals for these estimates are wide. Subjects themselves may not recall their own school performance. However, there is some evidence that long-term memories are preserved in early stages of dementia. For the 36 respondents in this study for whom proxies provided information, the proxies may have inadequately reported school performance or the respondent's level of education. It is important on principle to include those with proxy reports, so that even older adults with advanced frailty and cognitive impairment can be included in studies $[38,39]$. In our study, only 36 proxy informants answered the question on school performance. When their responses were excluded, the effect of "below average" school performance remained the same. Moreover, the question "How well did you perform in school?" is subjective in its interpretation. Some individuals may focus on one set of skills (verbal ability, mathematics, and biology) instead of others. Differential item functioning may occur, where a question is interpreted differently in people of different groups: in this case, possibly race/ethnic groups. We were limited by power to examine other types of dementia or cognitive impairment separately. Because the follow-up of ADAMS is incomplete, we cannot examine to what extent our findings were affected by ascertainment bias. Lastly, perhaps "cognitive dissonance" is involved, wherein participants with poor economic outcomes in adulthood attribute those outcomes to poor performance in school during early-life. Because our measure (self-assessed school performance) has not been extensively validated, future studies should assess the validity of this measure and link it to actual performance in school. Additional future studies could examine whether self-assessed school performance at the individual level is associated with measures of school quality.

\section{Conclusions}

This study suggests that a "below average" self-assessed school performance is associated with increased odds of $\mathrm{AD}$ in late life. Because this is a preliminary study, further studies of self-assessed school performance are recommended. Efforts to increase cognitive reserve early in life and throughout the life course are important, not only in themselves, but also as a possible protective mechanism to stave off the onset of AD. Thus, not only is "staying in school" important, but increasing school performance is equally important to diminish the potential long-reaching effects of low educational quality.

\section{Acknowledgments}

K.M.M. is supported by Research Career Scientist Award NIA-K-01AG025444-01A1 from the National Institute on Aging, and is affiliated with the Center for Aging in Diverse
Communities at the University of California at San Francisco, part of the Resource Centers for Minority Aging Research Program (funded by the National Institute on Aging, the National Institute of Nursing Research, and the National Center for Minority Health and Health Disparities) (Grant \# P30-AG-15272). K.M.L. was supported by grants K08AG019180 and R01-AG027010 from the National Institute on Aging and by a Paul Beeson Physician Faculty Scholars in Aging Research Award. The Health and Retirement Study is sponsored by grant NIA-U01AG009740 from the National Institute of Aging, and is conducted by the University of Michigan. The Aging, Demographics, and Memory Study was sponsored by grant U01-AG009740 from the National Institute of Aging. This work was presented as an oral presentation at the Annual Meeting of the Gerontology Society of America in 2007 (San Francisco, CA).

\section{References}

[1] Caamano-Isorna F, Corral M, Montes-Martinez A, Takkouche B. Education and dementia: a meta-analytic study. Neuroepidemiology 2006; 26:226-32.

[2] Zhang MY, Katzman R, Salmon D, Jin H, Cai GJ, Wang ZY, et al. The prevalence of dementia and Alzheimer's disease in Shanghai, China: impact of age, gender, and education. Ann Neurol 1990;27:428-37.

[3] Mortimer JA, Borenstein AR, Gosche KM, Snowdon DA. Very early detection of Alzheimer neuropathology and the role of brain reserve in modifying its clinical expression. J Geriatr Psychiatry Neurol 2005;18:218-23.

[4] Richards M, Deary IJ. A life course approach to cognitive reserve: a model for cognitive aging and development? Ann Neurol 2005; 58:617-22.

[5] Stern Y. What is cognitive reserve? Theory and research application of the reserve concept. J Int Neuropsychol Soc 2002;8:448-60.

[6] Manly JJ, Jacobs DM, Sano M, Bell K, Merchant CA, Small SA, et al. Cognitive test performance among nondemented elderly African Americans and whites. Neurology 1998;50:1238-45.

[7] Manly JJ, Jacobs DM, Sano M, Bell K, Merchant CA, Small SA, et al. Effect of literacy on neuropsychological test performance in nondemented, education-matched elders. J Int Neuropsychol Soc 1999; 5:191-202.

[8] Barnes DE, Tager IB, Satariano WA, Yaffe K. The relationship between literacy and cognition in well-educated elders. J Gerontol [A] Biol Sci Med Sci 2004;59:390-5.

[9] Mehta KM, Simonsick EM, Rooks R, Newman AB, Pope SK, Rubin SM, et al. Black and white differences in cognitive function test scores: what explains the difference? J Am Geriatr Soc 2004; $52: 2120-7$.

[10] UNESCO. EFA global monitoring report. Understanding educational quality; 2005.

[11] Heeringa SG, Fisher GG, Hurd M, Langa KM, Ofstedal MB, Plassman BL, et al. Institute for Social Research. Aging, Demographics and Memory Study (ADAMS) sample design, weighting and analysis: University of Michigan; 2006.

[12] Plassman BL, Langa KM, Fisher GG, Heeringa SG, Weir DR, Ofstedal MB, et al. Prevalence of cognitive impairment without dementia in the United States. Ann Intern Med 2008;148:427-34.

[13] Plassman BL, Langa KM, Fisher GG, Heeringa SG, Weir DR, Ofstedal MB, et al. Prevalence of dementia in the United States: the Aging, Demographics, and Memory Study. Neuroepidemiology 2007; 29:125-32.

[14] Herzog AR, Wallace RB. Measures of cognitive functioning in the AHEAD Study. J Gerontol [B] Psychol Sci Soc Sci 1997;52:37-48. 
[15] Juster FT, Suzman R. An overview of the Health and Retirement Study. J Hum Resources 1995;30(Suppl):S7-56.

[16] Langa KM, Plassman BL, Wallace RB, Herzog AR, Heeringa SG, Ofstedal MB, et al. The Aging, Demographics, and Memory Study: study design and methods. Neuroepidemiology 2005;25:181-91.

[17] Ashendorf L, Jefferson AL, Green RC, Stern RA. Test-retest stability on the WRAT- 3 reading subtest in geriatric cognitive evaluations. J Clin Exp Neuropsychol 2009;31:605-10.

[18] Moody-Ayers S, Lindquist K, Sen S, Covinsky KE. Childhood social and economic well-being and health in older age. Am J Epidemiol 2007;166:1059-67.

[19] Irwin M, Artin KH, Oxman MN. Screening for depression in the older adult: criterion validity of the 10-item Center for Epidemiological Studies Depression Scale (CES-D). Arch Intern Med 1999;159:1701-4.

[20] Bennett DA, Wilson RS, Schneider JA, Evans DA, Mendes de Leon CF, Arnold SE, et al. Education modifies the relation of AD pathology to level of cognitive function in older persons. Neurology 2003;60:1909-15.

[21] Manly JJ, Touradji P, Tang MX, Stern Y. Literacy and memory decline among ethnically diverse elders. J Clin Exp Neuropsychol 2003; 25:680-90.

[22] Lee DJ, Trapido E, Rodriguez R. Self-reported school difficulties and tobacco use among fourth- to seventh-grade students. J School Health 2002;72:368-73.

[23] Riley KP, Snowdon DA, Desrosiers MF, Markesbery WR. Early life linguistic ability, late life cognitive function, and neuropathology: findings from the Nun Study. Neurobiol Aging 2005;26:341-7.

[24] Fritsch T, Smyth KA, McClendon MJ, Ogrocki PK, Santillan C, Larsen JD, et al. Associations between dementia/mild cognitive impairment and cognitive performance and activity levels in youth. J Am Geriatr Soc 2005;53:1191-6.

[25] Whalley LJ, Starr JM, Athawes R, Hunter D, Pattie A, Deary IJ. Childhood mental ability and dementia. Neurology 2000;55:1455-9.

[26] Borenstein AR, Copenhaver CI, Mortimer JA. Early-life risk factors for Alzheimer disease. Alzheimer Dis Assoc Disord 2006;20:63-72.

[27] Borenstein AR, Wu Y, Mortimer JA, Schellenberg GD, McCormick WC, Bowen JD, et al. Developmental and vascular risk factors for Alzheimer's disease. Neurobiol Aging 2005;26:325-34.

[28] Moceri VM, Kukull WA, Emanual I, van Belle G, Starr JR, Schellenberg GD, et al. Using census data and birth certificates to re- construct the early-life socioeconomic environment and the relation to the development of Alzheimer's disease. Epidemiology 2001; 12:383-9.

[29] Shadlen MF, Larson EB, Gibbons LE, Rice MM, McCormick WC, Bowen J, et al. Ethnicity and cognitive performance among older African Americans, Japanese Americans, and Caucasians: the role of education. J Am Geriatr Soc 2001;49:1371-8.

[30] Bohnstedt M, Fox PJ, Kohatsu ND. Correlates of Mini-Mental Status Examination scores among elderly demented patients: the influence of race-ethnicity. J Clin Epidemiol 1994;47:1381-7.

[31] Fillenbaum G, Heyman A, Williams K, Prosnitz B, Burchett B. Sensitivity and specificity of standardized screens of cognitive impairment and dementia among elderly black and white community residents. J Clin Epidemiol 1990;43:651-60.

[32] Fillenbaum GG, Hughes DC, Heyman A, George LK, Blazer DG. Relationship of health and demographic characteristics to Mini-Mental State Examination score among community residents. Psychol Med 1988;18:719-26.

[33] Murden RA, McRae TD, Kaner S, Bucknam ME. Mini-Mental State Exam scores vary with education in blacks and whites. J Am Geriatr Soc 1991;39:149-55.

[34] O'Connor DW, Pollitt PA, Treasure FP, Brook CP, Reiss BB. The influence of education, social class and sex on Mini-Mental State scores. Psychol Med 1989; 19:771-6.

[35] Teresi JA, Golden RR, Cross P, Gurland B, Kleinman M, Wilder D. Item bias in cognitive screening measures: comparisons of elderly white, Afro-American, Hispanic and high and low education subgroups. J Clin Epidemiol 1995;48:473-83.

[36] Steele CM, Aronson J. Stereotype threat and the intellectual test performance of African Americans. J Pers Soc Psychol 1995;69:797-811.

[37] Haas SA. The long-term effects of poor childhood health: an assessment and application of retrospective reports. Demography 2007; 44:113-35.

[38] Corder LS, Woodbury MA, Manton KG. Proxy response patterns among the aged: effects on estimates of health status and medical care utilization from the 1982-1984 long-term care surveys. J Clin Epidemiol 1996;49:173-82.

[39] Neumann PJ, Araki SS, Gutterman EM. The use of proxy respondents in studies of older adults: lessons, challenges, and opportunities. J Am Geriatr Soc 2000;48:1646-54. 